\title{
The Distribution Characteristics of a 19-bp Indel of the PLAG1 Gene in Chinese Cattle
}

\author{
Zihui Zhou ${ }^{1,+}$, Bizhi Huang ${ }^{2,+}$, Zhenyu Lai ${ }^{1}$, Shipeng Li ${ }^{1}$, Fei Wu ${ }^{1}$, Kaixing Qu ${ }^{2}$, Yutang Jia ${ }^{3}$, \\ Jiawen Hou ${ }^{1}$, Jianyong Liu ${ }^{2}$, Chuzhao Lei ${ }^{1}$ and Ruihua Dang ${ }^{1, *(D)}$ \\ 1 Key Laboratory of Animal Genetics, Breeding and Reproduction of Shaanxi Province, College of Animal \\ Science and Technology, Northwest A\&F University, Xianyang 712100, China; 15636110299@163.com (Z.Z.); \\ lzy18408210600@126.com (Z.L.); lsp17782767206@163.com (S.L.); 18392360732@163.com (F.W.); \\ houjiawen@163.com (J.H.); leichuzhao1118@126.com (C.L.) \\ 2 Yunnan Academy of Grassland and Animal Science, Kunming 650212, China; hbz@ynbp.cn (B.H.); \\ Kaixqu@163.com (K.Q.); ljy@ynbp.cn (J.L.) \\ 3 Institute of Animal Science and Veterinary Medicine, Anhui Academy of Agriculture Science, Hefei 230001, \\ China; yutang2018@163.com \\ * Correspondence: dangruihua@nwsuaf.edu.cn; Tel.: +86-153-8862-7637 \\ + These authors contributed equally to this work.
}

Received: 29 October 2019; Accepted: 3 December 2019; Published: 4 December 2019

check for updates

Simple Summary: Growth traits are important quantitative traits for cattle performance, which influences herd productivity. Previous studies demonstrated that a 19-bp indel in pleomorphic adenoma gene 1 (PLAG1) is associated with bovine growth traits. In our studies, the distribution of the 19-bp indel of PLAG1 gene among 37 Chinese cattle breeds and the association between this indel and growth traits of Yunling cattle were explored. As a result, we found that the average body height of various Chinese cattle breeds showed an increasing trend from south to north of China, which was consistent with the distribution trend of the 19-bp indel in cattle at different geographic latitudes. Moreover, this indel was verified to be significantly associated with the growth traits of Yunling cattle. Our results showed that the 19-bp indel in PLAG1 strongly influences body size in Chinese cattle.

\begin{abstract}
Pleomorphic adenoma gene 1 (PLAG1) belongs to the PLAG family of zinc finger transcription factors. In cattle, a 19-bp insertion/deletion (indel) was identified in intron 1 of the PLAG1 gene (GenBank Accession No. AC_000171.1). Researches showed that the indel is polymorphic in Chinese cattle breeds such as Qinchuan cattle, Pinan cattle, Xianan cattle, and Jiaxian red cattle, and correlation analysis showed that the polymorphism is related to the height of these cattle breeds. Chinese cattle breeds show a difference in height related to geographical distribution. We investigated the distribution of the 19-bp indel polymorphism in 37 cattle breeds, including 1354 individuals. The results showed that there were three genotypes and two alleles (W, $366 \mathrm{bp}$; $\mathrm{D}, 347 \mathrm{bp}$ ). From northern cattle to southern cattle, the frequency of $\mathrm{W}$ allele gradually decreased, while the frequency of $\mathrm{D}$ allele showed an opposite trend, which was consistent with the distribution of cattle breeds of different height in China. Therefore, the polymorphism of this indel may be related to the regional distribution of cattle breeds in China. In addition, we chose Yunling cattle with a mixed genetic background to study the genetic effects of the 19-bp indel on body size traits. Statistical analysis showed that PLAG1 was significantly associated with the body height, cross height, and chest circumference of Yunling cattle $(p<0.05)$. This study provides new evidence that the 19-bp indel of the PLAG1 gene is a highly effective trait marker that can be used as a candidate molecular marker for cattle breeding.
\end{abstract}

Keywords: cattle; growth traits; indel; PLAG1 gene; polymorphism 


\section{Introduction}

As a kind of livestock with important economic value, cattle play an indispensable role in animal husbandry. According to geographical distribution, cattle in China are divided into central cattle (Qinchuan cattle, Nanyang cattle, Luxi cattle, Jinnan cattle, etc.), northern cattle (Mongolian cattle, Yanbian cattle, and Kazakh cattle), and southern cattle (Ji'an cattle, Jinjiang cattle, Wannan cattle, Weining cattle, etc.) [1]. Due to regional differences, there are significant differences in the body height traits of cattle breeds in different regions. The application of molecular marker polymorphisms and other techniques can provide a basis for the classification of Chinese cattle and the screening of body height traits [2].

Pleomorphic adenoma gene 1 (PLAG1) is involved in cell proliferation by directly regulating a wide array of target genes, including a number of growth factors such as IGF2 [3]. The PLAG family is composed of PLAG1, PLAGL1/LOT1/ZAC1, and PLAGL2, and its structure and function are highly conservative [4]. Genetic studies found that PLAG1 regulates cell apoptosis and gap 1 (G1) cell-cycle arrest, and it is associated with the development of a variety of tumors such as adioblastoma. Genome-wide association analysis showed that single nucleotide polymorphisms (SNPs) located in the PLAG1 gene region were closely related to adult height [5]. Also, PLAG1 is an important candidate gene affecting the growth and development of domestic animals. Some studies showed that the PLAG1 gene plays a certain regulatory role in milk production, reproductive performance, muscle formation, and body height of livestock [6,7]. In pigs, the PLAG1 gene has a certain effect on the length of limb bones [8]. In mice, knockout of the PLAG1 gene showed that growth and development were blocked [9]. In addition, it was found that the 19-bp insertion/deletion (indel) polymorphism (rs523753416) detected on the intron of chromosome 14 of PLAG1 gene was widespread in Qinchuan cattle [10], Pinnan cattle, Xia' nan cattle, Jiaxian red cattle, and other Chinese cattle, and it was related to the height of cattle, but the frequency distribution was quite different.

Based on this background, determining whether the 19-bp indel affected the body height between northern and southern cattle breeds in China was the aim of our study. The polymorphism of the 19-bp indel in different areas of China was investigated, and its relationship with the growth and development of Yunling cattle was analyzed to verify its extensive effects. The detection of genes potentially associated with economic traits and the identification of effective mutations can provide a basis for the molecular marker-assisted selection of livestock.

\section{Materials and Methods}

\subsection{Animals and Data Collection}

The study sample had a total of 1354 individuals, 37 breeds of adult cattle, including three northern breeds $(N=81)$, seven Central Plains breeds $(N=180), 23$ southern breeds $(N=555)$, two commercial breeds $(N=463)$, and two breeds for control $(N=48)$ and Tibetan cattle $(\mathrm{N}=27)$. The distribution of the 37 cattle breeds of China, as well as Angus and Holstein populations, is shown in Table S1 (Supplementary Materials).

According to the improved phenol-chloroform method [11], genomic DNA of 1354 individuals representing 37 breeds of Chinese cattle, Angus cattle, and Holstein cattle was extracted from bovine blood, and the growth data of 451 Yunling cattle individuals were quantified, including 10 body size indexes such as body height, hip cross height, body length, heart girth, chest width, rump length, chest depth, hip width, hucklebone width, and hip circumference, which were measured according to the method described by Gilbert et al. [12].

\subsection{Primer Design and PCR Amplification}

The insertion/deletion site (No. AC_000171.1 25020872-25020890) was genotyped using a pair of primers. The primers were designed on the National Center for Biotechnology Information (NCBI) Primer BLAST and synthesized by Shanghai Sangon Biotech Engineering Co., Ltd. The purification 
method was High Affinity Purification (HAP). A total of 2 OD divided into two tubes was provided. the size and sequence of the primers, the product fragment size, and $\operatorname{Tm}\left({ }^{\circ} \mathrm{C}\right)$ are shown in Table 1.

Table 1. Information on primer sets used in this study. F-forward; R-reverse.

\begin{tabular}{cccc}
\hline Primer Sequences $\left(\mathbf{5}^{\prime}-\mathbf{3}^{\prime}\right)$ & Primer Size $(\mathbf{b p})$ & Product Length $(\mathbf{b p})$ & $\mathbf{T m}\left({ }^{\circ} \mathbf{C}\right)$ \\
\hline F: AAAAGAGTCCGCGTTTACTGC & 21 & $366 / 347$ & 57 \\
R: CGATGAACTCTCCACCTGCG & 20 & & \\
\hline
\end{tabular}

The PCR reaction system was $12.5 \mu \mathrm{L}$, and the contents of each component were as follows: 10 pmol of each primer, $6.25 \mu \mathrm{L}$ of $2 \times$ PCR mix (Kangwei century biotechnology co., LTD, Beijing, China), $0.5 \mu \mathrm{L}$ of each primer, $10 \mathrm{ng}$ of genomic DNA, and $4.75 \mu \mathrm{L}$ of $\mathrm{ddH}_{2} \mathrm{O}$. The procedure of PCR amplification was as follows: pre-denaturation at $95{ }^{\circ} \mathrm{C}$ for $5 \mathrm{~min}$, denaturation at $95{ }^{\circ} \mathrm{C}$ for $30 \mathrm{~s}$, annealing at $57^{\circ} \mathrm{C}$ for $30 \mathrm{~s}$, extension at $72{ }^{\circ} \mathrm{C}$ for $30 \mathrm{~s}, 35$ cycles, and extension at $72{ }^{\circ} \mathrm{C}$ for $10 \mathrm{~min}$. The PCR instrument was from Hema Medical Instrument Co., Ltd (GuangDong, China). PCR amplification products were genotyped by $10 \%$ polyacrylamide gel electrophoresis at $220 \mathrm{~V}$ for about $2 \mathrm{~h}$ [13]. A total of 10 PCR products were selected and sent to Shanghai Sangon Biotech (Shanghai, China) for sequencing. The instrument for sequencing was ABI 3730xl in Shanghai Sangon Biotech (Shanghai, China).

The allele frequency and genotype frequency were determined according to the method of Maeiulla et al. The calculation formulas were as follows [14]:

Genotype frequency $(\mathrm{FA} i \mathrm{~A} j)=\mathrm{A} i \mathrm{~A} j$ number of individuals/total number of samples;

$$
\text { Allele frequency }(\mathrm{FA} i)=\mathrm{FA} i \mathrm{~A} j+1 / 2 \mathrm{FA} i \mathrm{~A} j \text {. }
$$

The Hardy-Weinberg equilibrium (HWE) [15] was tested, and population genetic indices such as gene heterozygosity $\mathrm{He}$, gene homozygosity $\mathrm{Ho}(\mathrm{He}+\mathrm{Ho}=1)$, effective allele number $(\mathrm{Ne})$, and polymorphism information content (PIC) were calculated.

$$
\begin{gathered}
H_{0}=\sum_{i=1}^{n} P_{i}^{2} \\
H_{e}=1-\sum_{i=1}^{n} P_{i}^{2} \\
N_{e}=1 / \sum_{i=1}^{n} P_{i}^{2} \\
\text { PIC }=1-\sum_{i=1}^{m} P_{i}^{2}-\sum_{i=1}^{m-1} \sum_{j=i+1}^{m} 2 P_{i}^{2} P_{j}^{2}
\end{gathered}
$$

The association between the 19-bp indel locus in the PLAG1 gene of Yunling cattle and its partial height traits was analyzed by SPSS 19.0 software (Statistical Product and Service Solutions, Version 19.0 Edition, IBM, Armonk, NY, USA) for one-way analysis of variance (ANOVA). The linear model used was as follows:

$$
\mathrm{Y} i j=\mu+\mathrm{A} i+\mathrm{I} j+\mathrm{E} i j
$$

where Yij is the trait measured on each of the $i j$-th animals, $\mu$ is the overall population mean of each trait, $\mathrm{A} i$ is fixed effect due to the $i$-th age, $\mathrm{I} j$ is the fixed effect associated with the $j$-th genotype, and $E i j$ is the random residual error. The data were corrected by the least-squares method, and the 
genotype frequency and allele frequency were obtained according to the above method using Popgene software [16].

\section{Results}

\subsection{PCR Amplification and Polyacrylamide Gel Electrophoresis}

According to the primer of the PLAG1 gene designed by Sangon Biotech, the length of the PCR amplified fragment was predicted to be $366 \mathrm{bp}$.

PCR amplification products were genotyped by $10 \%$ polyacrylamide gel electrophoresis. The bands of the electrophoresis were clear and bright, the length of the bands was consistent with the prediction, and three genotype bands were present, which were WW, DD, and WD. The sequencing results of this site are also consistent with the results displayed by the running gel (Figure 1).

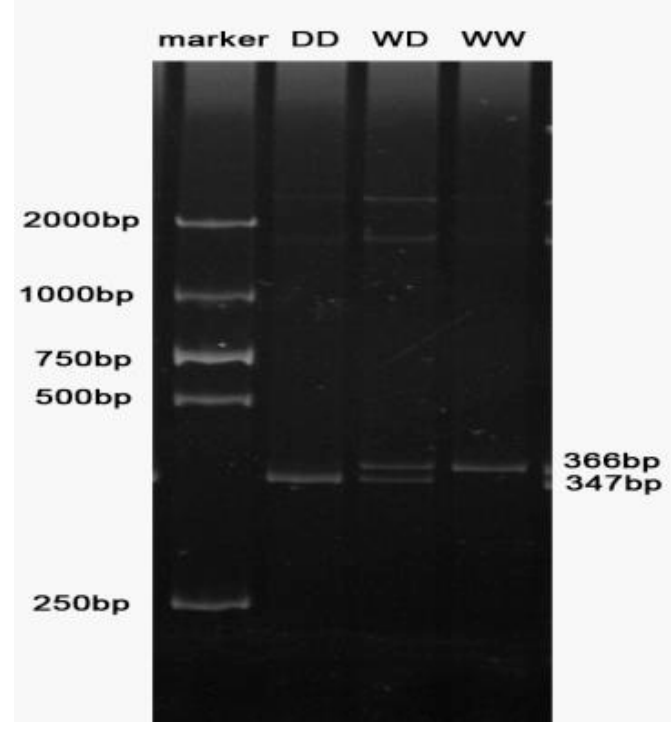

(a)

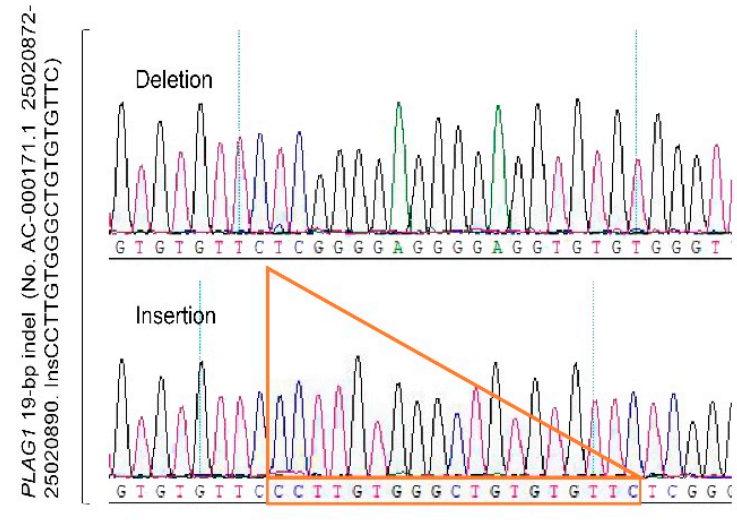

(b)

Figure 1. (a) The result of polyacrylamide gel electrophoresis. (b) The results of sanger sequencing.

\subsection{Regional Difference of Allele Frequency}

According to the regional information of the breeds classified in Animal Genetic Resources In China-Bovines, the results showed that, in the northern group, the frequencies of the $\mathrm{W}$ and $\mathrm{D}$ alleles were 0.78 and 0.22 , respectively, and the frequency of allele $\mathrm{W}$ accounted for the majority. In the central group, the frequencies of the $\mathrm{W}$ and $\mathrm{D}$ alleles were 0.51 and 0.49 , respectively, and the frequencies of the two alleles were nearly equal. In the southern group, the frequencies of the $W$ and $D$ alleles were 0.31 and 0.69 , respectively, and the frequency of the $\mathrm{W}$ allele was lower. Similar to the results of the northern and central groups, in the commercial group, the frequencies of the $\mathrm{W}$ and $\mathrm{D}$ alleles were 0.59 and 0.41 , respectively, and the frequency of the $\mathrm{W}$ allele was also higher than the $\mathrm{D}$ allele. The geographical distribution and allele frequencies of each breed are shown in Figure 2. In addition to the 35 domestic breeds shown in the figure below, for the allele frequencies of two foreign breeds used as the control, Angus cattle and Holstein cattle, the frequencies of the $\mathrm{W}$ allele were 0.68 and 0.65 , respectively, and the frequencies of the $\mathrm{D}$ allele were 0.32 and 0.35 , respectively. The results of genotypic and allele frequencies of the PLAG1 gene across the 37 cattle breeds are shown in Table S2 (Supplementary Materials). Meanwhile, the average body height of these cattle breeds is also given in Table S2 (Supplementary Materials) [17]. 


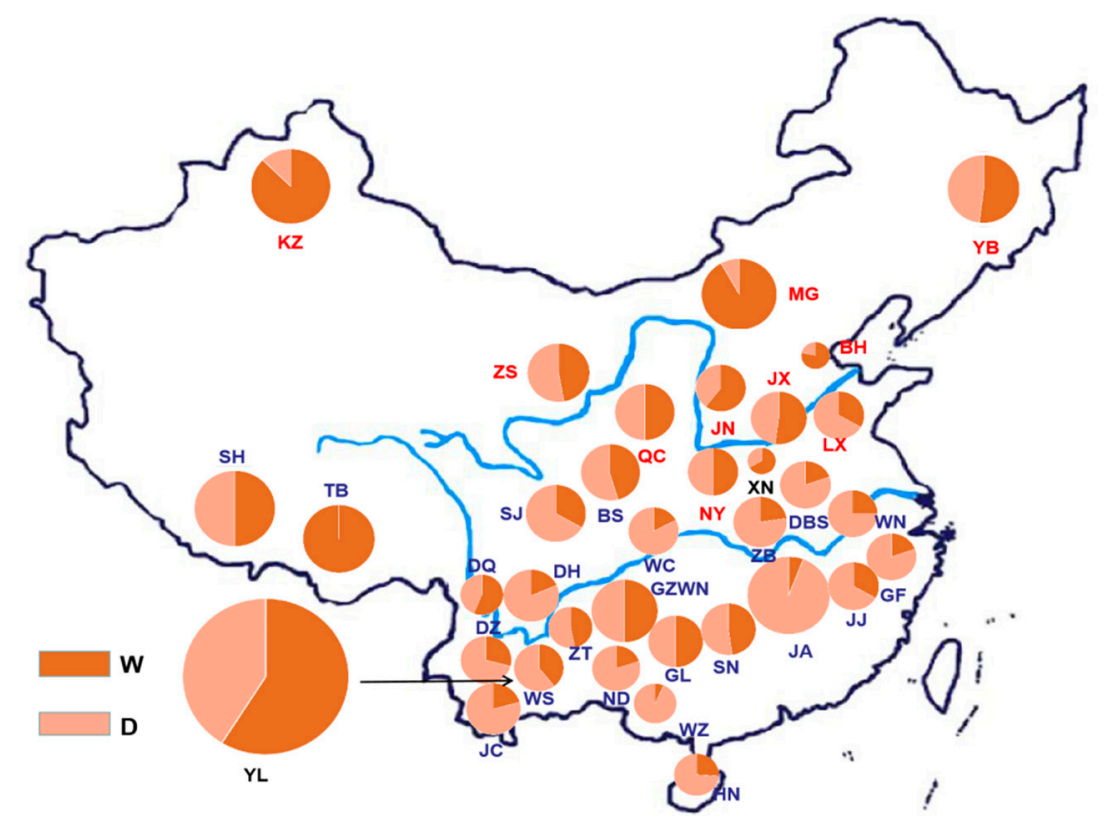

Figure 2. Distribution of allele frequency of the PLAG1 gene in Chinese breeds. BH, Bohai Black; BS, Bashan; DBS, Dabeishan; DH, dehong; DQ, Diqing; DZ, Dianzhong; GF, Guangfeng; GL, Guanling; GZWN, Weining; JA, Ji'an; JC, Jiangcheng; JJ, Jinjiang; JN, Jinnan; JX, Jiaxian red; KZ, Kazakh; LX, Luxi; MG, Mongolian; ND, Nandan; NY, Nanyang; QC, Qinchuan; SJ, Sanjiang; SH, Shigatse Humped; SJ, Sanjiang; SN, sinan; TB, Tibetan; WC, Wuchuan; WL, Wuling; WN, Wannan; WS, Wenshan; XN, xianan; YB, Yanbian; YL, Yunling; ZB, Zaobei; ZS, Zaosheng; ZT, Zhaotong.

\subsection{Verification of Population Genetic Effects of PLAG1 Gene in Yunling Cattle}

After analysis of genetic polymorphism indicators such as genotype, genotype frequencies, allelic frequencies, heterozygosity (He), effective allele (Ne), and the polymorphic information content (PIC) of the PLAG1 polymorphism, the results are shown in Tables 2 and 3. According to the Botstein polymorphic information content classification standard, Yunling cattle had medium genetic diversity in the indel locus [18]. The point belongs to a moderate polymorphism, and the dominant genotype of the PLAG1 gene is $\mathrm{WD}$, whereas the dominant allele is $\mathrm{W}$, and the polymorphic information content is 0.37. By using SPSS (19.0) software, a one-way analysis of variance (ANOVA) of the Yunling cattle PLAG1 gene and its height traits was performed. The polymorphism of this gene was significantly correlated with body height, hip cross height, and chest circumference of the Yunling cattle population, as shown in Table 4.

Table 2. Genotypic and allelic frequencies (\%) of bovine PLAG1 gene.

\begin{tabular}{|c|c|c|c|c|c|c|c|c|c|c|}
\hline \multirow{2}{*}{ Breed } & \multicolumn{3}{|c|}{ Genotype } & \multirow{2}{*}{$\begin{array}{c}\text { Samples } \\
N\end{array}$} & \multicolumn{3}{|c|}{ Genotype Frequencies } & \multicolumn{2}{|c|}{ Allelic Frequencies } & \multirow{2}{*}{$\begin{array}{c}\text { HWE } \\
p \text {-Value }\end{array}$} \\
\hline & WW & WD & DD & & $p$-ww & $p$-WD & $p$-DD & $p_{\text {-W }}$ & $p_{\text {-D }}$ & \\
\hline YL & 154 & 223 & 74 & 451 & 0.34 & 0.5 & 0.16 & 0.59 & 0.41 & 0.65 \\
\hline
\end{tabular}

WW, indel wild type; WD, heterozygous type; DD, deleted type. $N$, cattle number. HWE, Hardy-Weinberg equilibrium $\chi^{2}$ value. YL, Yunling.

Table 3. Genetic diversity parameters in YL.

\begin{tabular}{cccc}
\hline Breed & Ne & PIC & He \\
\hline YL & 1.94 & 0.37 & 0.48
\end{tabular}

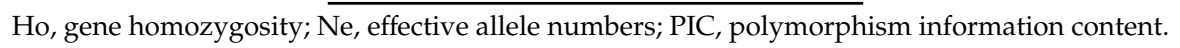


Table 4. Statistical association analysis of bovine PLAG1 gene indel with growth traits in Yunling.

\begin{tabular}{ccccc}
\hline \multirow{2}{*}{ Growth Traits } & \multicolumn{3}{c}{ Genotype (Mean \pm SE) } & \multirow{2}{*}{$p$-Value } \\
\cline { 2 - 4 } & WW & WD & DD & \\
\hline Body height $(\mathrm{cm})$ & $129.17 \pm 5.86^{\mathrm{b}}$ & $130.41 \pm 5.49^{\mathrm{a}}$ & $128.95 \pm 4.91^{\mathrm{b}}$ & $0.041^{*}$ \\
Hip cross height $(\mathrm{cm})$ & $131.65 \pm 15.06^{\mathrm{b}}$ & $134.26 \pm 5.65^{\mathrm{a}}$ & $132.61 \pm 5.31^{\mathrm{ab}}$ & $0.039^{*}$ \\
Body length $(\mathrm{cm})$ & $155.92 \pm 15.70$ & $154.39 \pm 13.78$ & $153.96 \pm 8.93$ & 0.482 \\
Heart girth $(\mathrm{cm})$ & $196.58 \pm 12.65^{\mathrm{ab}}$ & $197.91 \pm 10.99^{\mathrm{a}}$ & $193.95 \pm 11.42^{\mathrm{b}}$ & $0.039^{*}$ \\
Chest width $(\mathrm{cm})$ & $49.24 \pm 5.48$ & $49.27 \pm 4.95$ & $48.89 \pm 5.00$ & 0.855 \\
Rump length $(\mathrm{cm})$ & $50.51 \pm 3.24$ & $50.36 \pm 3.79$ & $49.65 \pm 3.66$ & 0.224 \\
Chest depth $(\mathrm{cm})$ & $68.95 \pm 6.06$ & $68.73 \pm 5.94$ & $67.85 \pm 5.24$ & 0.408 \\
Hip width $(\mathrm{cm})$ & $57.80 \pm 5.79$ & $57.96 \pm 5.78$ & $56.73 \pm 6.33$ & 0.288 \\
Hucklebone width $(\mathrm{cm})$ & $22.47 \pm 2.30$ & $22.29 \pm 2.49$ & $22.19 \pm 1.95$ & 0.631 \\
Hip circumference $(\mathrm{cm})$ & $113.37 \pm 12.25$ & $112.66 \pm 8.83$ & $112.73 \pm 8.34$ & 0.787 \\
\hline
\end{tabular}

$\mathrm{LSM} \pm \mathrm{SE}$, least-squares means and their standard errors for each genotypic class reported. ${ }^{\mathrm{a}, \mathrm{b}}$ Means significantly different for genotype frequencies with genetic groups $\left({ }^{*}, p<0.05\right)$.

\section{Discussion}

The 19-bp indel analyzed in the cattle PLAG1 gene in this study is located in the intron region. Although introns are non-coding regions, they contain many cis-acting elements that bind to trans-acting factors to regulate gene transcription. Intronic mutations often act as enhancers or silencers to regulate gene transcription [19]. Also, intronic mutations can affect protein expression by affecting the shear and stability of target gene messenger RNA (mRNA), or by imbalanced chain intronic mutations and causal mutations [20]. Polymorphisms found in the intron region of the human CXCR3 gene were verified to inhibit gene expression [21]. Similarly, the 20-bp indel polymorphism identified in the sheep PRNP gene also affected the expression of other growth-related genes [22].

The northern and central cattle are mainly found in the high latitudes of China and are relatively tall compared to the lower latitudes in the south. Our results showed that the distribution of allele frequency of the northern and central cattle was related to the distribution of their body height. With the increase in the latitude of cattle breeds, the $\mathrm{W}$ allele frequency also showed an increasing trend. This result was also reflected in the control groups. One of the controls, Holstein cattle, is native to the province of North Holland and West Friesland in the north of the Netherlands [23] (latitude information: $49^{\circ}-53^{\circ}$ ). The height of adult Holstein cattle can reach $155-175 \mathrm{~cm}$. Meanwhile, the height of the control Angus cattle (latitude information: 50-58 ${ }^{\circ}$ ) was also higher than that of most cattle breeds in China [24]. In the results, we also found that the body height of the central group cattle is higher than the northern group (Table S2, Supplementary Materials), which may be related to hybrid vigor and resource environment in the Central Plains [17].

In order to verify its wide effect, the 19-bp indel in 27 Tibetan cattle was detected in this study, and it was found that the allele frequencies of $\mathrm{W}$ and $\mathrm{D}$ were 1 and 0 , respectively. However, according to the body size data, Tibetan cattle are smaller than other breeds in size. This may be related to the high-altitude hypoxic environment of Tibetan cattle and their isolation from other Chinese cattle species.

In addition, in order to further verify the reliability of this marker, the variants of this polymorphism and its influence on growth traits were also detected in Yunling cattle, which has a mixed genetic background bred from brahmin cattle, Murray grey cattle, and Yunnan cattle by ternary hybridization.

The results showed that the polymorphism of the PLAG1 gene 19-bp indel in Yunling cattle was significantly correlated with its body size, indicating that the gene locus had a strong population genetic effect. However, in order to explore the mechanism of the association between the indel and cattle growth traits, further studies are still needed on the internal mechanism of the PLAG1 gene at the transcription and translation levels. 


\section{Conclusions}

Our research investigated the distribution of the 19-bp indel polymorphism of the PLAG1 gene in 37 cattle breeds, including 1354 individuals, and we found that, in this locus, the frequencies of the W and $\mathrm{D}$ alleles show a regular distribution from the northern cattle groups to the southern cattle groups, consistent with their different height in China. Furthermore, we found that, in Yunling cattle, the 19-bp indel polymorphism of PLAG1 was significantly correlated with body height, cross height, and chest circumference $(p<0.05)$. These results suggested that the 19-bp indel of the PLAG1 gene is an effective marker for growth traits in Chinese cattle.

Supplementary Materials: The following are available online at http://www.mdpi.com/2076-2615/9/12/1082/s1: Table S1: Distribution of 37 cattle breeds of China, as well as Angus and Holstein populations; Table S2: Genotypic and allele frequencies of the PLAG1 gene across 37 cattle breeds.

Author Contributions: Conceptualization, Z.Z.; data curation, Z.Z.; formal analysis, Z.Z.; investigation, B.H., Y.J., and S.L.; methodology, Z.Z., Z.L., and F.W.; project administration, B.H. and J.H.; supervision, R.D., J.L., and K.Q.; validation, R.D. and C.L.; writing—original draft, Z.Z.; writing—review and editing, R.D.

Funding: This work was financially supported by the National Natural Science Foundation of China (81770514), the Science and Technology Project of Yangling of China (2018NY-33), the Program of the National Beef Cattle and Yak Industrial Technology System (CARS-37), the Program of Yunling Scholar, the Young and Middle-aged Academic Technology Leader Backup Talent Cultivation Program in Yunnan Province, China (No. 2018HB045), and the Yunnan Provincial Major S\&T Project (2019ZG007, 2019ZG011).

Conflicts of Interest: The authors declare no conflicts of interest.

\section{References}

1. Wood, R.W. On a remarkable case of uneven distribution of light in a diffraction grating spectrum. Lond. Edinb. Dublin Philos. Mag. J. Sci. 1902, 4, 396-402. [CrossRef]

2. Hou, J.; Qu, K.; Jia, P.; Hanif, Q.; Zhang, J.; Chen, N.; Dang, R.; Chen, H.; Huang, B.; Lei, C. A SNP in PLAG1 is associated with body height trait in Chinese cattle. Anim. Genet. 2019. [CrossRef] [PubMed]

3. Van Dyck, F.; Declercq, J.; Braem, C.V.; Van de Ven, W.J. PLAG1, the prototype of the PLAG gene family: Versatility in tumour development (review). Int. J. Oncol. 2007, 30, 765-774. [CrossRef]

4. Smith, E.A.; Erickson, M.G.; Ulijasz, A.T.; Weisblum, B.; Corn, R.M. Surface plasmon resonance imaging of transcription factor proteins: Interactions of bacterial response regulators with DNA arrays on gold films. J. Langmuir. 2003, 19, 1486-1492. [CrossRef]

5. Gudbjartsson, D.F.; Walters, G.B.; Thorleifsson, G.; Stefansson, H.; Halldorsson, B.V.; Zusmanovich, P.; Sulem, P.; Thorlacius, S.; Gylfason, A.; Steinberg, S.; et al. Many sequence variants affecting diversity of adult human height. Nat. Genet. 2008, 40, 609-615. [CrossRef]

6. Fink, T.; Tiplady, K.; Lopdell, T.; Johnson, T.; Snell, R.G.; Spelman, R.J.; Davis, S.R.; Littlejohn, M.D. Functional confirmation of PLAG1 as the candidate causative gene underlying major pleiotropic effects on body weight and milk characteristics. Sci. Rep. 2017, 7, 44793. [CrossRef]

7. Yanase, Y.; Hiragun, T.; Kaneko, S.; Gould, H.J.; Greaves, M.W.; Hide, M. Detection of refractive index changes in individual living cells by means of surface plasmon resonance imaging. Biosens. Bioelectron. 2010, 26, 674-681. [CrossRef]

8. Guo, Y.; Hou, L.; Zhang, X.; Huang, M.; Mao, H.; Chen, H.; Ma, J.; Chen, C.; Ai, H.; Ren, J.; et al. A meta analysis of genome-wide association studies for limb bone lengths in four pig populations. BMC Genet. 2015, 16, 95. [CrossRef]

9. Juma, A.R.; Damdimopoulou, P.E.; Grommen, S.V.; Van de Ven, W.J.; De Groef, B. Emerging role of PLAG1 as a regulator of growth and reproduction. J. Endocrinol. 2016, 228, R45-R56. [CrossRef]

10. Xu, W.; He, H.; Zheng, L.; Xu, J.W.; Lei, C.Z.; Zhang, G.M.; Dang, R.H.; Niu, H.; Qi, X.L.; Chen, H.; et al. Detection of 19-bp deletion within PLAG1 gene and its effect on growth traits in cattle. Gene 2018, 675, 144-149. [CrossRef]

11. Wang, J.Y.; Yu, Y.; Feng, L.X.; Wang, H.Z.; Zhang, Q. Genomic DNA extraction from hair sacs of pigs using modified phenol-chloroform method. Yi Chuan 2010, 32, 752-756. [CrossRef] [PubMed] 
12. Wang, J.Y.; Yu, Y.; Feng, L.X.; Wang, H.Z.; Zhang, Q. Linear body measurements of cattle before and after 20 years of selection for postweaning gain when fed two different diets. J. Anim. Sci. 1993, 71, 1712-1720.

13. Weber, K.; Osborn, M. The reliability of molecular weight determinations by dodecyl sulfate-polyacrylamide gel electrophoresis. J. Biol. Chem. 1969, 244, 4406-4412. [PubMed]

14. Robinson, J.D.; Coffman, A.J.; Hickerson, M.J.; Gutenkunst, R.N. Sampling strategies for frequency spectrum-based population genomic inference. BMC Evol. Biol. 2014, 14, 254.

15. Zeng, Y.; Hu, R.; Wang, L.; Gu, D.; He, J.; Wu, S.-Y.; Ho, H.-P.; Li, X.; Qu, J.; Gao, B.Z. Recent advances in surface plasmon resonance imaging: Detection speed, sensitivity, and portability. Nanophotonics 2017, 6, 1017-1030. [CrossRef]

16. Yeh, F.C.; Yang, R.; Boyle, T. POPGENE VERSION 1.31-Microsoft Window-Based Freeware for Population Genetic Analysis Quick User Guide; Centre for International Forestry Research: Bogor, Indonesia, 1999; pp. 12-25.

17. China National Commission of Animal Genetic Resources. Animal genetic resources in China-Bovines; China National Commission of Animal Genetic Resources: Beijing, China, 2011; pp. 17-227.

18. Botstein, D.; White, R.L.; Skolnick, M.; Davis, R.W. Construction of a genetic linkage map in man using restriction fragment length polymorphisms. Am. J. Hum. Genet. 1980, 32, 314-331. [PubMed]

19. Pennacchio, L.A.; Bickmore, W.; Dean, A.; Nobrega, M.A.; Bejerano, G. Enhancers: Five essential questions. Nat. Rev. Genet. 2013, 14, 288-295. [CrossRef]

20. Barrett, L.W.; Fletcher, S.; Wilton, S.D. Regulation of eukaryotic gene expression by the untranslated gene regions and other non-coding elements. Cell. Mol. Life Sci. 2012, 69, 3613-3634. [CrossRef]

21. Cheong, H.S.; Park, C.S.; Kim, L.H.; Park, B.L.; Uh, S.T.; Kim, Y.H.; Lym, G.I.; Lee, J.Y.; Lee, J.K.; Kim, H.T.; et al. CXCR3 polymorphisms associated with risk of asthma. Biochem. Biophys. Res. Commun. 2005, 334, 1219-1225. [CrossRef]

22. Zhou, C.; Jin, W.; Zhang, Y.; Yang, M.; Xiang, L.; Wu, Z.; Jin, Q.; Mu, Y. An angle-scanning surface plasmon resonance imaging device for detection of mismatched bases in caspase-3 DNA. Anal. Methods 2013, 5, 2369-2373. [CrossRef]

23. Jordan, C.E.; Frutos, A.G.; Thiel, A.J.; Corn, R.M. Surface plasmon resonance imaging measurements of DNA hybridization adsorption and streptavidin/DNA multilayer formation at chemically modified gold surfaces. Anal. Chem. 1997, 69, 4939-4947. [CrossRef]

24. Wang, Y.F.; Lang, Y.M.; Huang, B.Z.; Feng, Y.H.; Li, H.P.; Zhang, S.S.; Xie, P.; Sun, B.Z. The Quality Evaluation of Different Anatomical Locations of Yunling Cattle. China Anim. Husb. Vet. Med. 2017, 44, 708-716. 